Please do not remove this page

RMIT

UNIVERSITY

\title{
Autonomous production tracking for augmenting output in off-site construction
}

Arashpour, Mehrdad; Wakefield, Ron; Blismas, Nick; Maqsood, Tayyab

https://researchrepository.rmit.edu.au/esploro/outputs/9921862323101341/filesAndLinks?institution=61RMIT_INST\&index=null

Arashpour, M., Wakefield, R., Blismas, N., \& Maqsood, T. (2015). Autonomous production tracking for augmenting output in off-site construction. Automation in Construction, 53, 13-21.

https://doi.org/10.1016/j.autcon.2015.03.013

Document Version: Accepted Manuscript

Published Version: https://doi.org/10.1016/j.autcon.2015.03.013

Repository homepage: https://researchrepository.rmit.edu.au

(C) 2015 Elsevier B.V. All rights reserved.

Downloaded On 2023/04/26 15:18:01 +1000

Please do not remove this page 
Thank you for downloading this document from the RMIT Research Repository.

The RMIT Research Repository is an open access database showcasing the research outputs of RMIT University researchers.

RMIT Research Repository: http://researchbank.rmit.edu.au/

\section{Citation:}

Arashpour, M, Wakefield, R, Blismas, N and Maqsood, T 2015, 'Autonomous production tracking for augmenting output in off-site construction', Automation in Construction, vol. 53, pp. $13-21$

See this record in the RMIT Research Repository at:

https://researchbank.rmit.edu.au/view/rmit:30558

Version: Accepted Manuscript

Copyright Statement: (c) 2015, Elsevier. Licensed under the Creative Commons Attribution-NonCommercial-NoDerivatives 4.0 International http://creativecommons.org/licenses/by-nc-nd/4.0/

Link to Published Version:

http://dx.doi.org/10.1016/j.autcon.2015.03.013 


\section{Autonomous Production Tracking for Augmenting Output in Off-site Construction}

(1)

(1) (5)

\section{Abstract:}

Problems in existing methods of production tracking in off-site construction result in schedule delays and increased costs. To eliminate these deficiencies, an autonomous production tracking that analyzes real-time production data is proposed. A specific implementation of the proposed production tracking mechanisms has been developed for a large off-site construction plant in Australia, and is in the process of installation. The paper shows that: (i) The production model in off-site construction is always nonlinear in the outcome due to the presence of variability (ii) In systems with a periodic production target, deviation from the schedule converges to zero at the end of production period and the same downward trend should be followed in designing plan buffers (iii) Long-term production performance in off-site construction can autonomously be monitored and controlled by observing critical variables of production. The paper provides those who manage off-site construction with recommendations on effective production tracking and management. The models and propositions in this research are of practical value and can be used to detect impending production shortfalls against periodic targets in the short-term, and adjust capacity parameters and production targets in long-term planning.

Keywords: Autonomous control; Construction management; Flexible capacity; Lean production; Off-site construction; Production Planning; Simulation; Workflow 


\section{Introduction}

Off-site production (OSP) is an increasingly popular approach in construction that relocates some on-site operations to a more controlled factory environment. OSP is a unique hybrid of manufacturing and construction and can be described as a series of construction operations on a progressive assembly line. It offers several advantages over traditional site-built construction such as superior quality [1], swift delivery [2], improved health and safety [3], and customization capability [4]. The competitive advantage of off-site manufacturers over their on-site counterparts has its roots in different factors such as broad adoption of information technology, modern equipment, and innovative production layouts.

Although OSP is the fastest growing segment of the construction industry [5], there are production challenges that hamper its performance. These production challenges are related to high levels of product mix [6], traditional supply chain configurations [7], engineering faults and rework [8], management decisions [9], and cyclic market demand [10]. Adverse effects of these production challenges are eventually translated to the manufacturing floor and together with process dependencies generate bottlenecks. Delays are closely associated with bottlenecks as there are frequent work starvations downstream and blockages upstream [11]. Delays create a gap between planned production and actual output and prevent OSP making scheduled commitments. Real-time production tracking in OSP must provide short term information (e.g. by hour or shift) regarding progress toward production targets and long term information (e.g. by day or week) regarding capacity parameters and demand planning [12].

The necessity of providing a production tracking system with both accurate short term and long term outputs highlights the importance of developing tailored mechanisms that can evaluate the real-time production performance in off-site construction. This requires detection of impending 
shortfalls with regard to the production target and updating production plans in accordance with operations-level changes occurring on the manufacturing floor. To this end, this paper describes a customized methodology for production tracking in off-site construction as the most important part of managing workflow in any production environment (shop floor control). First, a description of previous studies is provided to identify gaps resulting in previously presented research. Next, a model of production output in off-site construction is developed and the underlying mathematical background is briefly explained. Then, empirical data is used to detect impending production shortfalls against periodic targets in short-term planning. Finally, longterm capacity tracking and feedback mechanisms in off-site construction are discussed and related propositions are developed.

\section{Research background}

Although production planning and control systems have been widely investigated by researchers [13-15], there is still much scope to develop customized systems that are tailored for the unique conditions of the construction industry $[16,17]$. Traditional techniques for construction planning and control are only able to manage stationary bottlenecks. Such techniques are too coarse and often require an excessive number of jobs under construction to prevent work starvation of the bottleneck [18]. Previous research suggests borrowing production initiatives from manufacturing and the use of workflow leveling strategies such as 'even flow production' in construction [19]. Although useful, such initiatives are too restrictive for production planning in off-site construction. In fact, they are more appropriate for highly repetitive processes of house building 
[20, 21]. Furthermore, they cannot manage floating bottlenecks that are closely related to different designs and product mixes in off-site construction [11].

Despite efforts in developing specialty production tracking systems for off-site construction, the industry has found the available systems unsatisfactory especially for large scale production. Mullens [22] indicates that realizing the fundamental differences between on-site and off-site construction is crucial to developing robust production control systems that work effectively on the manufacturing floor. For instance, resources in off-site construction are dedicated to processes and therefore the 'parade of trades'[23] proceeds quicker than in on-site construction. Furthermore, demand in off-site construction is usually translated to a periodic production target (quota) and it is non-trivial to measure the real-time progress towards these targets. Hence, the early detection of an impending production target shortfall is pivotal to identify timely corrective measures in off-site construction production.

A number of researchers have studied the development of production tracking mechanisms for site-built construction. For instance, Arditi, et al. [24] suggests the use of linear scheduling methods and line of balance to orchestrate the completion of work units at approximately the same rate. Production planning under resource constraints has also been explored in the context of on-site construction [25-28]. Furthermore, object-oriented models have been developed for projects with highly repetitive processes such as house building [29, 30]. However, there is little research that has explored the potential of developing customized production tracking mechanisms for off-site construction that can generate real-time feedback on the progress towards periodic production targets to adjust capacity parameters [31, 32]. In the next section, the process of autonomous production tracking in off-site construction will be discussed. 


\section{Research method}

Empirical research is conducted in this paper in order to analyze the impact of using an autonomous production tracking system on output in off-site construction. After reviewing relevant studies in the construction literature, the nonlinear model of production in off-site construction is developed and analyzed using conditional probability or Bayesian inference. The analytical model focuses on computing posterior probabilities of meeting scheduled targets given observations of production performance. Translating into probability language, let $B=$ "probability of missing the scheduled target", and $A=$ " a positive deviation from production plan". The objective is to calculate $P(B \mid A)$ and the Bayes' basic formula can be used for this purpose:

$P(B \mid A)=\frac{P(B \cap A)}{P(A)}=\frac{P(B \cap A)}{P(B \cap A)+P\left(B^{c} \cap A\right)}$

Where $P\left(B^{c}\right)$ is the probability of meeting (not missing) the scheduled production target. The multiplication rule is used to compute the probabilities on the right side of the equation:

$P(B \cap A)=P(B) \times P(A \mid B)$

Details about the analytical modeling approach are presented in section 4 of the paper. Following the analytical modeling of production tracking in off-site construction, empirical data is used to construct discrete event simulation (DES) experiments and detect impending production shortfalls against periodic targets in both short-term and long-term planning.

A large off-site construction plant in Australia was selected and several site observations were conducted to collect required production data. The off-site construction company builds several sizes and types of precast concrete tanks for industrial wastewater treatment plants. In the 
controlled environment of the plant, different products are made by placing concrete in reusable formwork and curing it to maximize strength and minimize permeability. All products comply with ACI 318-14 standards and are superior to cast-in-place concrete tanks in terms of construction time, durability, and resistance to development of stress fractures. Fig. 1 illustrates a simplified representation of an activity cycle diagram for building precast concrete tanks.

Fig.1. Schematic illustration of the workflow in off-site construction of precast concrete tanks

The off-site production data of particular interest in this research are processing times, instances of production shortage/overage, different product mixes, and availability of plan buffers. In order to have a fair comparison between production scenarios, three factors of production rate, resource availability, and rework rate were controlled for throughout the experimentation. In addition to site observations, automatic collection of real-time data in construction was conducted by using wireless data collection tools such as ultra-wideband (UWB) receivers and tags. Using UWB facilitated the implementation of the proposed production tracking system and tracing production input and output on the manufacturing floor to accurately compute real-time values of critical production variables. The process of using the collected data to construct analytical models and simulation experiments are explained in details in the following sections of the paper.

\section{Mathematical representation of production tracking in off-site construction (shop floor control)}


The development of a tailored tracking mechanism for off-site production (OSP) is motivated by two important considerations. In the short term (e.g. by hour or shift) the main objective is to detect impending production shortfalls early enough so that timely corrective measures can be implemented to remedy the problem. In the long term (e.g. by day or week), information provided by the production tracking system is used for adjusting capacity parameters and periodic targets of construction production. There are two commonly used set of techniques in OSP for tracking and management of production. The first set includes network analysis techniques such as Critical Path Method (CPM) and Project Evaluation and Review Technique (PERT), which have dominated the industry. Efforts have been made to strengthen and improve these techniques [33, 34]. However, they will almost certainly result in biased production models in OSP as interactions between resources are not fully captured and their main focus is on scheduling, not causing events to conform to the schedule [35, 36].

The second set of techniques for tracking and management of production in OSP focuses on managing workflow in the production environment (shop floor control). The aim of this set of techniques is to form a decision support system that suggests feasible sequences for production processes and also address the issue of bottleneck management [37]. Furthermore, the shop floor control system is usually equipped with a real-time simulator of off-site construction processes that traces high priority (hot) jobs in the network and adjust capacity parameters accordingly. This approach to production tracking is the focus of the current research and its major properties as relevant to the goals and discussions in this paper will be presented. The notation and symbols used for this purpose are listed in the appendix.

In order to model the production in off-site construction, the length of regular time production is defined as $[0, T t]$. Let $A p$ represent the actual production in standard units. If the scheduled 
production $S p$ is being set periodically (e.g. by week), the cumulative production at any timet $=$ $R t$ (e.g. by shift) should be equal to $S p \times R t / T t$. The particular figure of interest is the deviation from the production target $(d)$ and can be computed using Eq. [3]:

$d=A p-(S p \times R t / T t)$

where $d$ indicates the amount by which the actual production output is ahead/behind the scheduled production target $(S p)$ at any time $t=R t$. As can be seen in Fig. 2, if the quantity of $d$ is positive, the actual production (dashed line) is ahead of schedule (dotted line) at time $R t$; If negative, then the production is behind the scheduled target.

Fig.2. Production tracking in off-site construction production

Fig. 2 provides valuable feedback on the real-time status of off-site construction during the production period. The solid line in this Figure represents a Lower Control Limit $(L C L)$ of -3 standard deviations. Production status can follow three different scenarios. In the best case scenario $(d \geq 0)$, the actual production $(A p)$ is greater than or equal to the scheduled production target $(S p)$. However, in real-world production in off-site construction there are usually levels of deviation from the schedule and actual production is behind the schedule $(L C L<A p<S p)$. This situation calls for appropriate corrective measures such as assigning overtime, switching work assignments, and hiring contract labor in order to expedite the construction production. Finally, in the worst case scenario, actual production is below the lower control limit and the chance of making the scheduled production is almost zero (probability $=0.135 \%$ ). Deviation from the production target and therefore nonlinearity of the production output model is caused by 


$$
d \leq A p_{(T t-R t)}-\frac{S p(T t-R t)}{T t}
$$

\section{$E q \cdot[4]$}

188 Where $T t-R t$ is the time left to produce $S p$. Probability of missing the scheduled target is:

$P($ missing the schedule $)=P\left[d>A p_{(T t-R t)}-\frac{S p(T t-R t)}{T t}\right]$

Hence, the probability of making the scheduled target by time $T t$ is:

$$
1-P\left[d>A p_{(T t-R t)}-\frac{S p(T t-R t)}{T t}\right] \quad E q .[6]
$$

which yields

$P($ making the schedule $)=1-\Phi\left[\frac{d-(\mu-S p)(T t-R t)}{T t}\right] \times\left[\sigma \sqrt{\frac{T t-R t}{T t}}\right]^{-1}$ 
deviation from scheduled production that defines the chances of making/missing the schedule in off-site construction. This leads to the second proposition in this paper:

Proposition 2 Probability of making/missing a periodic production target in off-site construction is dependent on the real-time deviation from the scheduled production target.

The real-time probability of making the scheduled production can be plotted (Fig. 3) to generate updated feedback on the progress towards periodic production targets and adjusting capacity parameters.

Fig.3. Real-time evaluation of production performance in off-site construction

This Figure gives an at-a-glance indication of the real-time status of construction production. The probability of missing the schedule is less $(5 \%<P<50 \%)$ when the deviation from the planned target is positive ( $d>0$ on the left side of the Figure). Missing the periodic production target (quota) is more probable ( $50 \%<P<95 \%)$ when $d<0$ and there is shortage with regard to the scheduleat $t=R t$. For example, if the shortage level at time $t=20$ is equal to -5 standard units of production, the probability of missing the scheduled target lies exactly on 60 per cent in Fig. 3. Understandably, this Figure is symmetrical around its center, indicating that even if there is no deviation (overage/shortage) from the scheduled production $(d=0)$, the probability of missing the scheduled target at the end of production period $(t=T t)$ stands at $50 \%$. As the offsite producer becomes more risk averse, a lower probability of missing scheduled commitments is sought. In such cases, use of plan buffers and flexible capacity can mitigate workflow variability on the manufacturing floor [42]. Flexible capacity can be achieved by using multiskilled resources or intentional underutilization of production capacity [43-45]. Figures 4(a) to 
4(c) illustrate the relationship between real-time deviation from production target and the probability of missing the target when the scheduled production $(S p)$ is equal to $100 \%, 95 \%$ and $80 \%$ of the capacity, respectively.

Fig.4(a). Production tracking graph (Scheduled target = capacity)

Fig. 4(b). Production tracking graph (Scheduled production $=95 \%$ of capacity)

Fig. 4(c). Production tracking graph (Scheduled production $=80 \%$ of capacity)

Production tracking in the above Figures has shorter intervals and is updated in accordance to operational-level changes occurring in off-site construction. Fig. 4(a) is symmetrical around its center as the scheduled production and capacity are exactly equal. Figures 4(b) and 4(c), however, are asymmetrical because there is flexible capacity in the production system. As a result, when there is no deviation from the scheduled production $(d=0)$, the probability of missing the schedule in Figures $4(\mathrm{~b})$ and $4(\mathrm{c})$ is reduced to $45 \%$ and $38 \%$ respectively. This result confirms findings of Walsh, et al. [46] and Im, et al. [47], and advances the following proposition:

Proposition 3 The probability of missing periodic production targets in off-site construction is determined by the level of available flexible capacity in the production system.

A specific implementation of the proposed production tracking mechanisms has been developed for a large off-site construction plant in Australia. The following section describes how raw data is transformed and used by the production tracking mechanisms to monitor production 
performance for both short-term and long-term planning purposes. Further propositions of the research will also be advanced in the following sections.

\section{Empirical research}

In order to examine the robustness and effectiveness of the production tracking methodology, empirical data were collected and used in constructing discrete event simulation (DES) experiments.

\subsection{The framework of the simulation experiments}

A series of discrete event simulation experiments were performed using data collected from a large off-site manufacturer in Australia that builds precast concrete tanks for industrial wastewater treatment plants. The experiments evaluated the short term performance of the tracking mechanisms in detecting impending production shortfalls. Furthermore, long term performance in adjusting capacity parameters and demand planning was examined. Table 1 presents 11 major activities in off-site construction of precast concrete tanks and three-point estimates of their duration.

Table 1. Activities and their input data in the off-site production of precast concrete tanks

Note that this table only contains a small portion of a much larger record of data points collected. As an example, building the tank floor slab contains several processes such as preparation of the formworks, placing the designed steel mesh, using plastic spacers to ensure the minimum coverage for the steel mesh, pouring, and curing concrete. Care was taken to utilize detail processing data in simulation modeling to ensure a true representation of real-world system behavior. The experimental framework is described in the following section. 


\subsection{Experimental design}

In each experiment, data from the real system were collected and different production scenarios were analyzed by varying duration of production, shortage/overage levels, distribution of processing times, product mix, and the level of capacity flexibility. In each experiment, different commonly used standard theoretical probability distributions such as Normal, Beta, Triangular, Erlang, Gamma, and Exponential were fitted to processing times. In each case, the quality of the fit was evaluated using goodness-of-fit tests in the @RISK probability distribution fitting software. Real-time deviation from periodic production targets $(d)$ was recorded on an hourly basis with an accuracy of $99 \%$.

\section{Deviation from periodic production targets in off-site construction}

Fig. 5 shows Probability Density Function (PDF) of a sample chronological record of the data points collected in five selected experiments.

Fig.5. Probability Density Function (Deviation from periodic production target)

In each production scenario, an average of 500 instances of deviation from scheduled production was recorded. Results in Fig. 5 are consistent with Proposition 2, confirming that level of realtime deviation from the production schedule determines probability of missing/making the schedule at the end of production period. Figure 5 shows that the average level of deviation is at its highest level at the start of production $(R t=0)$. However, by proceeding towards the end of the period, the mean value of deviation levels reduce significantly. Furthermore, the cumulative distribution function (CDF) of the production shortage shows how the standard deviation of the variable of interest also declines over the course of production (see Fig. 6). 
Fig.6. Cumulative Distribution Function (Deviation from periodic production target)

As can be seen in Figures 5 and 6, the actual output in early stages of the production is far behind the schedule. However, difference between scheduled target and actual production declines when approaching the end of production period. This is because near the end of the period, there is not much of the periodic production target (quota) remaining and consequently big capacity cushions cannot increase chances of meeting the target. This is in line with findings of Hong and Hastak [11], González, et al. [48] and Koo, et al. [49], and leads us to the following proposition:

Proposition 4 Use of capacity cushions or plan buffers in off-site construction is more effective at the start rather than the end of the production period.

The above proposition suggests that there is more opportunity for improvement at the beginning of the production period, when project deadlines are not too close. Production tracking mechanisms proposed in this paper can be used to improve the output in off-site production (OSP). Based on Proposition 1, the production model of OSP is nonlinear in outcome as there is always variability in the system. Hence, the chance of making a periodic production target is 5050, provided that scheduled target and capacity are equal and the production is exactly on schedule. Proposition 2 suggests that conditional probability can be used to examine the shortterm progress towards a periodic target, given the level of real-time deviation in OSP. Based on Proposition 3, flexible capacity can increase the probability of making the scheduled target. Finally, Proposition 4 suggests that due to the dynamics of production in off-site construction, incremental improvements over time should be sought. 
Once the production tracking system has fulfilled its short-term task of computing the probability of making/missing the schedule, simple and effective visualization of production, similar to Figures 4 to 6 can be used to generate signals when the probability falls below (or rises above) specified levels. For instance, when the probability of missing a periodic production target reaches higher levels than $60 \%$, off-site production managers should diagnose the problem swiftly and address it by rescheduling tasks and switching work assignments. When the probability of missing schedule reaches a very high level, then top management should consider serious corrective measures such as hiring contract labor and/or assigning overtime. In OSP, very low probability of missing periodic production targets may be of interest as well. For example, if a resource is shared by multiple processes from which a process has a very low chance of missing the schedule, it makes sense to engage the resource with another process with a higher probability of missing the scheduled target.

The level of deviation from scheduled targets can provide valuable insight into the dynamics of production in off-site construction. In the designed experiments, real-time levels of production deviation were recorded and used to elicit information about the behavior of the production system. Figures 7(a) and 7(b) illustrate the trend of production deviation in the experiments.

Fig.7 (a). Decreasing level of deviation from scheduled target over the course of production

Fig. 7 (b). Downward trend of deviation from scheduled target over the course of production

In OSP systems with a periodic production target, the objective is to meet the schedule every period. Analysis of production parameters in the experiments show that level of deviation from target gradually decreases and finally converges to zero at the end of the production period. This 
confirms that optimum amount of flexible capacity is not constant over the course of production and is a function of the production time. This is in line with findings of González, et al. [48] and Arashpour, et al. [50] leads to the following proposition:

Proposition 5 In off-site construction systems with periodic production targets, deviation from the schedule converges to zero at the end of a given production period. In order to optimize the size of capacity buffers, downward trend of production deviation should be translated to consecutive reductions in the buffer size.

The above proposition can be implemented on the manufacturing floor by visualization of production tracking data similar to Figures 7(a) and 7(b). The following section focuses on longterm capacity tracking and its potential to provide input to other planning modules in order to objectively evaluate the production performance in off-site construction.

\section{Long-term capacity tracking and feedback mechanism in off-site construction}

In the long-term, information provided by capacity tracking is used as input to other planning modules such as workforce and aggregate planning. Since periodic targets are set in off-site production (OSP), the main observable variable will be the time to make these targets. This is unique to OSP and calls for tailored capacity tracking and shop floor control mechanisms. These mechanisms should be able to evaluate the performance of OSP systems over the long term and need to acquire real-time data from the manufacturing floor to fulfill their task [51-53]. However, collecting real-time production data is not a trivial task and often considered as the main 
limitation for long-term capacity tracking in off-site construction [50, 54]. Automatic collection of real-time data in construction can be facilitated by using wireless data collection tools such as ultra-wideband (UWB) receivers and tags [55]. Using UWB enables OSP manufacturers to trace production input and output on the manufacturing floor and accurately compute real-time values of critical production variables such as mean $(\mu)$ and standard deviation $(\sigma)$ of production. Due to the ubiquitous presence of variability in both construction processes and market demand, actual production $(A p)$ in OSP always fluctuates. Hence, it is necessary to smooth past data to adjust capacity parameters so that they are not excessively sensitive to noise [56, 57]. Exponential smoothing can be used to provide an updated estimate of production parameters using real-time data. Table 2 shows a sample of smoothed mean, variance and standard deviation of production over 14 days. Note that this table only contains a small portion of a much larger record of data points collected.

\section{Table 2. Sample of critical values of production and their exponentially smoothed values}

As can be seen in Table 2, smoothed values of production variables are less sensitive to noise and depending on the importance (weight) of the past observations, single or double exponential smoothing can be used. Table 2 shows how smoothed production mean has smaller values at the beginning of the period and increases gradually towards the end. Standard deviation of production, however, has an opposite trend and decreases over the course of production. Results from real-time observation of critical values in OSP have potential to provide an at-a-glance indication of long-term performance in OSP and lead to the final proposition of this research:

Proposition 6 Long-term production performance in off-site construction can autonomously be monitored by observing critical variables of production. 
Tracing critical values of production, such as smoothed mean and standard deviation, can show whether or not management efforts for improvement are having positive effects on the production performance. Fig. 8, for example, plots the smoothed values of mean and standard deviation over the course of production.

Fig.8. Critical variables of production

As can be seen in Fig. 8, smoothed mean capacity of production is trending up reaching a peak of 55 standard units of production at the end of the period. Smoothed standard deviation of capacity, however, is trending down, decreasing from a peak of 12.15 to a low of 1.03 . This indicates that performance of off-site production has improved over the course of production. Management should diagnose and address problems on the manufacturing floor, if trends were in opposite direction.

\section{Summary and discussion}

This research demonstrated the possibility and potential of having an autonomous production tracking system in off-site construction. The analytical models (Section 4) already incorporated two production tracking techniques - controlling real-time deviation from the scheduled production target and level of available flexible capacity in the system. The subsequent simulation experiments incrementally tested the effectiveness of plan buffers at different stages of production and the idea of reducing the size of such buffers towards the end of production course.

The series of discrete event simulation experiments were performed using data collected from a large off-site construction manufacturer in Australia that builds precast concrete tanks for 
industrial wastewater treatment plants. In each experiment, different production scenarios were analyzed by varying duration of production, shortage/overage levels, distribution of processing times, product mix, and the level of capacity flexibility.

Findings revealed that the model of production output in off-site construction is nonlinear. This is due to the ubiquitous presence of variability in OSP environments. This nonlinear function can be interpreted using conditional probability or Bayesian inference in order to understand whether or not production is on track to make the scheduled commitments. The results of analysis clearly show that chances of meeting the production target are reasonably high when the quota is not set equal to the capacity and a proper capacity buffer is in place. The optimum size for capacity buffers is not uniform over the course of production and smaller buffers are required when approaching project milestones for convergence of actual and scheduled production. Finally, performance in off-site construction can be autonomously monitored by using the critical values of production. The tracking mechanisms are predictable and provide both managerial information on real-time production status and input to other long-term planning functions such as workforce and aggregate planning.

The findings extend those of Benjaoran and Dawood [31] and Pan, et al. [32], confirming that an effective shop floor control in off-site construction can augment production outputs significantly.

\section{Conclusions}

Prior work has documented different production issues in off-site construction and proposals to improve the situation such as innovative production line configurations, material handling technologies, and process automation[32, 58-60]. However, these studies have not focused on where planning and control meet processes. A customized shop floor control methodology for 
off-site production (OSP) is required to effectively manage the production flow [22]. Hence, the presented paper describes a tailored methodology for production tracking and control in off-site construction. The extracted knowledge from production control can help diagnosing potential issues in the process of production.

This work contributes to the current body of knowledge by proposing customized mechanisms for shop floor control in off-site construction. The models and propositions in this research are of practical value and can be used in order to measure progress against a performance target in the short-term, and also collecting and validating capacity data in the long-term. Improvements recorded in this study have a great potential to be achievable in a range of off-site operations from heavy construction to house building to infrastructure projects.

Production tracking and shop floor control in off-site construction is not a trivial task in the presence of variability caused by processing time randomness, product mix, and shared resources. Future research should develop comprehensive control strategies for a real-time evaluation of production performance. In conducting such research, concurrent use of analytical heuristics and simulation tools is likely to be essential.

\section{Acknowledgements}

This paper is based upon work supported in part by the RMIT School of Graduate Research, through HDRPG Grant. Opinions expressed are those of the writers and not necessarily those of RMIT University.

\section{Appendix. Notation and symbols}

Ap Actual production (cumulative)

$d \quad$ Deviation from production target 
$444 \quad E($.$) \quad Expected value$

$445 \quad L C L \quad$ Lower Control Limit

$446 \quad$ Rt Real time

$447 \quad S p \quad$ Scheduled production target (cumulative)

$448 \quad T t \quad$ Target time (end of production)

$449 \mu \quad$ Avearage production in standard units

$450 \quad \sigma \quad$ Standard deviation of production

$451 \Phi($.$) \quad Standard normal distribution$

452

453

\section{References}

454 [1] N. Boyd, M. M. A. Khalfan, and T. Maqsood, "Off-site construction of apartment buildings," Journal of Architectural Engineering, vol. 19, pp. 51-57, // 2013.

456 [2] Q. Moya and O. Pons, "Improving the design and production data flow of a complex

[3] N. Blismas, C. Pasquire, and A. Gibb, "Benefit evaluation for off-site production in curvilinear geometric Glass Reinforced Concrete façade," Automation in Construction, vol. 38, pp. 46-58, 2014.

464 [5] I. Nahmens and M. Mullens, "Lean Homebuilding: Lessons Learned from a Precast Concrete Panelizer," Journal of Architectural Engineering, vol. 17, pp. 155-161, 2011. 
[6] N. Dawood and R. Marasini, "Visualisation of a stockyard layout simulator "SimStock": A case study in precast concrete products industry," Automation in Construction, vol. 12, pp. 113-122, 2003.

[7] L. Jaillon and C. S. Poon, "The evolution of prefabricated residential building systems in Hong Kong: A review of the public and the private sector," Automation in Construction, vol. 18, pp. 239-248, 2009.

[8] M. Arashpour, R. Wakefield, N. Blismas, and E. W. M. Lee, "Analysis of disruptions caused by construction field rework on productivity in residential projects," Journal of Construction Engineering and Management, vol. 140, 2014.

[9] A. Dong, M. L. Maher, M. J. Kim, N. Gu, and X. Wang, "Construction defect management using a telematic digital workbench," Automation in Construction, vol. 18, pp. 814-824, 2009.

[10] G. Polat, D. Arditi, G. Ballard, and U. Mungen, "Economics of on-site vs. off-site fabrication of rebar," Construction Management and Economics, vol. 24, pp. 1185-1198, 2006.

[11] T. Hong and M. Hastak, "Simulation study on construction process of FRP bridge deck panels," Automation in Construction, vol. 16, pp. 620-631, 2007.

[12] M. Nasereddin, M. A. Mullens, and D. Cope, "Automated simulator development: A strategy for modeling modular housing production," Automation in Construction, vol. 16, pp. 212-223, 2007.

[13] S. Y. L. Yin, H. P. Tserng, J. C. Wang, and S. C. Tsai, "Developing a precast production management system using RFID technology," Automation in Construction, vol. 18, pp. 677-691, 2009. 
[14] S. S. Leu and S. T. Hwang, "GA-based resource-constrained flow-shop scheduling model for mixed precast production," Automation in Construction, vol. 11, pp. 439-452, 2002.

[15] C. H. Ko and S. F. Wang, "GA-based decision support systems for precast production planning," Automation in Construction, vol. 19, pp. 907-916, 2010.

[16] M. Haller, W. Lu, L. Stehn, and G. Jansson, "An indicator for superfluous iteration in offsite building design processes," Architectural Engineering and Design Management, pp. 1-16, 2014.

[17] M. Arashpour and M. Arashpour, "A collaborative perspective in green construction risk management," in 37th Annual Conference Of The Australasian Universities Building Educators Association (AUBEA), 2012, pp. 1-11.

[18] A. Sawhney, K. D. Walsh, H. H. Bashford, and S. Palaniappan, "Impact of inspected buffers on production parameters of construction processes," Journal of construction engineering and management, vol. 135, pp. 319-329, 2009.

[19] H. H. Bashford, A. Sawhney, K. D. Walsh, and K. Kot, "Implications of even flow production methodology for U.S. housing industry," Journal of construction engineering and management, vol. 129, pp. 330-337, 2003.

[20] G. M. Winch, "Models of manufacturing and the construction process: The genesis of reengineering construction," Building Research and Information, vol. 31, pp. 107-118, 2003.

[21] S. D. Green and S. C. May, "Re-engineering construction: Going against the grain," Building Research and Information, vol. 31, pp. 97-106, 2003. 
[22] M. Mullens, "Production flow and shop floor control: Structuring the modular factory for custom homebuilding," in Proceedings of the NSF Housing Research Agenda Workshop, 2004, pp. 12-14.

[23] I. Tommelein, D. Riley, and G. Howell, "Parade Game: Impact of Work Flow Variability on Trade Performance," Journal of construction engineering and management, vol. 125, pp. 304-310, 1999.

[24] D. Arditi, O. B. Tokdemir, and K. Suh, "Scheduling system for repetitive unit construction using line-of-balance technology," Engineering Construction and Architectural Management, vol. 8, pp. 90-103, 2001.

[25] H. Li and H. Zhang, "Ant colony optimization-based multi-mode scheduling under renewable and nonrenewable resource constraints," Automation in Construction, vol. 35, pp. 431-438, 11// 2013.

[26] D. Chua, L. Shen, and S. Bok, "Constraint-Based Planning with Integrated Production Scheduler over Internet," Journal of construction engineering and management, vol. 129, pp. 293-301, 2003.

[27] F. Cheng, H. Li, Y. W. Wang, M. Skitmore, and P. Forsythe, "Modeling resource management in the building design process by information constraint Petri nets," Automation in Construction, vol. 29, pp. 92-99, // 2013.

[28] M. Arashpour, R. Wakefield, and N. Blismas, "Role of simulation in construction processes-harmony in capturing resources," in Research, Development and Practice in Structural Engineering and Construction (ASEA-SEC), 2013, pp. 1-5. 
[29] K. El-Rayes, R. Ramanathan, and O. Moselhi, "An object-oriented model for planning and control of housing construction," Construction Management and Economics, vol. 20, pp. 201-210, 2002.

[30] M. Arashpour, R. Wakefield, and N. Blismas, "Improving construction productivity: implications of even flow production principles," in CIB World Building Congress 2013: Construction and Society, 2013, pp. 1-12.

[31] V. Benjaoran and N. Dawood, "Intelligence approach to production planning system for bespoke precast concrete products," Automation in Construction, vol. 15, pp. 737-745, 2006.

[32] W. Pan, A. G. F. Gibb, and A. R. J. Dainty, "Strategies for integrating the use of off-site production technologies in house building," Journal of Construction Engineering and Management, vol. 138, pp. 1331-1340, 2012.

[33] M. Ammar, "LOB and CPM Integrated Method for Scheduling Repetitive Projects," Journal of Construction Engineering and Management, vol. 139, pp. 44-50, 2013.

[34] M. Hajdu, "Effects of the application of activity calendars on the distribution of project duration in PERT networks," Automation in Construction, 2013.

[35] G. Lee, R. Sacks, and C. Eastman, "Product data modeling using GTPPM - A case study," Automation in Construction, vol. 16, pp. 392-407, 2007.

[36] H. G. Ballard, "The last planner system of production control," PhD dissertation, University of Birmingham, 2000.

[37] R. Sacks, I. Kaner, C. M. Eastman, and Y. S. Jeong, "The Rosewood experiment Building information modeling and interoperability for architectural precast facades," Automation in Construction, vol. 19, pp. 419-432, 2010. 
[38] T. Hegazy, M. Said, and M. Kassab, "Incorporating rework into construction schedule analysis," Automation in Construction, vol. 20, pp. 1051-1059, 2011.

[39] M. Arashpour, R. Wakefield, N. Blismas, and E. W. M. Lee, "A new approach for modelling variability in residential construction projects," Australasian Journal of Construction Economics and Building, vol. 13, pp. 83-92, 2013.

[40] R. Sacks, M. Radosavljevic, and R. Barak, "Requirements for building information modeling based lean production management systems for construction," Automation in Construction, vol. 19, pp. 641-655, 2010.

[41] W. J. Hopp and M. L. Spearman, Factory physics: McGraw-Hill Irwin Irwin, 2008.

[42] G. Ballard and G. Howell, "Shielding production: Essential step in production control," Journal of Construction Engineering and Management, vol. 124, pp. 11-17, 1998.

[43] M. Arashpour, M. Shabanikia, and M. Arashpour, "Valuing the contribution of knowledge-oriented workers to projects: a merit based approach in the construction industry," Australasian Journal of Construction Economics and Building, vol. 12, pp. 112, 2012.

[44] M. Arashpour and M. Arashpour, "Important factors influencing personnel performance of construction companies," Economics, Business and Management, vol. 2, pp. 32-37, 2011.

[45] M. Arashpour and M. Arashpour, "Gaining the Best Value from HR in Construction Companies," Proceedings of the 6th European Conference on Management Leadership and Governance, pp. 23-33, 2010. 
[46] K. D. Walsh, A. Sawhney, and H. H. Bashford, "Production equations for unsteady-state construction processes," Journal of construction engineering and management, vol. 133, pp. 254-261, 2007.

[47] K. S. Im, S. H. Han, B. Koo, and D. Y. Jung, "Formulation of a pull production system for optimal inventory control of temporary rebar assembly plants," Canadian Journal of Civil Engineering, vol. 36, pp. 1444-1458, 2009.

[48] V. González, L. F. Alarcón, and K. Molenaar, "Multiobjective design of Work-In-Process buffer for scheduling repetitive building projects," Automation in Construction, vol. 18, pp. 95-108, 2009.

[49] K. J. Koo, S. K. Kim, and H. K. Park, "A simulation approach for a periodic PCR buffer allocation strategy in organizational program management," Automation in Construction, vol. 20, pp. 1020-1029, 2011.

[50] M. Arashpour, R. Wakefield, N. Blismas, and J. Minas, "Optimization of process integration and multi-skilled resource utilization in off-site construction," Automation in Construction, vol. 50, pp. 72-80, 2015.

[51] J. Meiling, F. Backlund, and H. Johnsson, "Managing for continuous improvement in offsite construction: Evaluation of lean management principles," Engineering, Construction and Architectural Management, vol. 19, pp. 141-158, 2012.

[52] E. C. W. Lou and K. A. M. Kamar, "Industrialized building systems: Strategic outlook for manufactured construction in Malaysia," Journal of Architectural Engineering, vol. 18, pp. 69-74, 2012.

[53] H. Johnsson and J. H. Meiling, "Defects in offsite construction: Timber module prefabrication," Construction Management and Economics, vol. 27, pp. 667-681, 2009. 
[54] M. Arashpour, R. Wakefield, N. Blismas, and E. W. M. Lee, "Framework for improving workflow stability: Deployment of optimized capacity buffers in a synchronized construction production," Canadian Journal of Civil Engineering, vol. 41, pp. 995-1004, 2014.

[55] A. H. Behzadan, Z. Aziz, C. J. Anumba, and V. R. Kamat, "Ubiquitous location tracking for context-specific information delivery on construction sites," Automation in Construction, vol. 17, pp. 737-748, // 2008.

[56] E. W. M. Lee, I. W. H. Fung, V. W. Y. Tam, and M. Arashpour, "A fully autonomous kernel-based online learning neural network model and its application to building cooling load prediction," Soft Computing, pp. 1-16, 2013/11/22 2013.

[57] B. Ashuri and J. Lu, "Time series analysis of ENR construction cost index," Journal of Construction Engineering and Management, vol. 136, pp. 1227-1237, // 2010.

[58] J. S. Goulding, F. Pour Rahimian, M. Arif, and M. D. Sharp, "New offsite production and business models in construction: priorities for the future research agenda," Architectural Engineering and Design Management, pp. 1-22, 2014.

[59] A. G. F. Gibb and F. Isack, "Re-engineering through pre-assembly: Client expectations and drivers," Building Research and Information, vol. 31, pp. 146-160, 2003.

[60] G. Maas and B. Van Eekelen, "The Bollard - The lessons learned from an unusual example of off-site construction," Automation in Construction, vol. 13, pp. 37-51, 2004. 